American Journal of Applied Sciences 5 (11): 1602-1604, 2008

ISSN 1546-9239

(C) 2008 Science Publications

\title{
Case Study: A Strategic Research Methodology
}

\author{
Khairul Baharein Mohd Noor \\ Universiti Industri Selangor, 40000, Shah Alam, Malaysia
}

\begin{abstract}
This research reviews the literature on case study as a strategic qualitative research methodology. Although case studies have been criticised by some authors as lacking scientific rigour and do not address generalizability, this research, however, reiterated its appropriateness when dealing with a process or a complex real-life activities in great-depth. Case study has been commonly used in social science fields like sociology, industrial relations and anthropology eventhough generally was considered an underutilized strategy. Hence, this research explained the general concept of a case study, strengths and weaknesses of using this method knowing that theoretically case is exciting and data rich. Based on a study of four organizations and the researcher's own experience, this article described matters on how case study was undertaken, gaining excess to those organizations and the systematic process of data collection and triangulation (multiple techniques). It was noted that combining multiple techniques for elicitng data in case study research actually strengthens and confirmed results.
\end{abstract}

Key words: Case study, research methodology, qualitative research, triangulation

\section{THE CHOICE OF RESEARCH METHODOLOGY}

The choice of which method to employ is dependent upon the nature of the research problem, Morgan and Smircich (1980) argue that the actual suitability of a research method, derives from the nature of the social phenomena to be explored ${ }^{[1]}$. There are basically two basic methodological traditions of research in social science, namely positivism and postpositivism (phenomenology).

Positivism is an approach to the creation of knowledge through research which emphasizes the model of natural science: the scientist adopts the position of objective researcher, who collects facts about the social world and then builds up an explanation of social life by arranging such facts in a chain of causality ${ }^{[2]}$.

In contrast, post-positivism is about a reality which is socially constructed rather than objectively determined. Hence the task of social scientist should not be to gather facts and measure how often certain patterns occur, but to appreciate the different constructions and meanings that people place upon their experience $^{[3]}$.

Positivism, thus, which is based on the natural science model of dealing with facts, is more closely associated with quantitative method of analysis. On the other hand, post-positivism that deals with understanding the subjectivity of social phenomena, requires a qualitative approach.
In explaining qualitative research, Denzin and Lincoln $^{[4]}$ state that, qualitative implies an emphasis on processes and meanings that are not rigorously examined, measured (if measured at all), in terms of quantity, amount, intensity, or frequency. Thus, there are instances, particularly in the social sciences, where researchers are interested in insight, discovery, and interpretation rather than hypothesis testing ${ }^{[5]}$.

\section{CASE STUDY AS A STRATEGIC METHODOLOGY}

In explaining what a case is, Yin suggests that the term refers to an event, an entity, an individual or even a unit of analysis. It is an empirical inquiry that investigates a contemporary phenomenon within its real life context using multiple sources of evidence ${ }^{[6]}$. Anderson $^{[7]}$ sees case studies as being concerned with how and why things happen, allowing the investigation of contextual realities and the differences between what was planned and what actually occurred. Case study is not intended as a study of the entire organization. Rather is intended to focus on a particular issue, feature or unit of analysis. In order to understand and examine the processes of training activities in organizations, case study method was chosen. This method enables me to understand the complex real-life activities in which multiple sources of evidence were used. The used of case study to probe an area of interest in depth is particularly appropriate as described by Patton ${ }^{[8]}$, Case studies become particularly useful where one needs to 
understand some particular problem or situation in great-depth, and where one can identify cases rich in information.

\section{STRENGTHS AND WEAKNESSES OF USING CASE STUDY METHOD}

Case studies have been criticised by some as lack of scientific rigour and reliability and that they do not address the issues of generalizability ${ }^{[9]}$. However, there are some strengths of case study. For example, it enables the researcher to gain an holistic view of a certain phenomenon or series of events ${ }^{[10]}$ and can provide a round picture since many sources of evidence were used.

Another advantage is that case study can be useful in capturing the emergent and immanent properties of life in organizations and the ebb and flow of organizational activity, especially where it is changing very fast ${ }^{[11]}$.

Case studies also allow generalizations as that result of findings using multiple cases can lead to some form of replication.

\section{HOW TO UNDERTAKE CASE STUDY RESEARCH?}

According to $\mathrm{Yin}^{[12]}$ there are there types of case study research exploratory, descriptive, and explanatory. Researchers in business related subjects sometimes limit case studies to the exploratory use. For example, pilot case study can be used as a basis for formulating questions or hypothesis testing. Descriptive case study is an attempt to describe, like what happen to a product when it is launched. Explanatory research can be useful for example to study processes in companies.

In my research I subscribed to descriptive case study where observations were conducted in four organizations and reporting them. The entire process of undertaking the case studies research is as shown in the diagram in Fig.1.

As shown in Fig. 1, the first stage of the research was doing an extensive literature on the subject studied by computer and manual methods. In addition, several discussions with the academic supervisor, colleagues and professional staff in selected organizations were also conducted to extract valuable information in order to construct a framework for this research. Opinions from professional staff and documents from selected companies were useful in gaining an early understanding of the topics that needed to be explored. This was followed by the formulation of a theoretical framework which formed a structure for the study. A set of research questions to be used in interviews was later constructed.

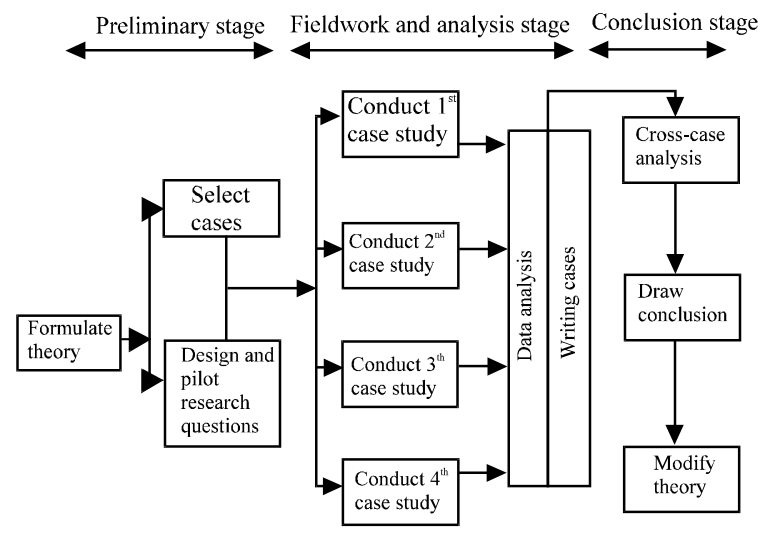

Fig. 1: Stafes involved in conduction case studies

\section{DESIGN AND PILOTING INTERVIEW QUESTIONS}

As the interview was the primary data gathering instrument for the research a semi-structured interview was chosen where questions were carefully designed to provide adequate coverage for the purpose of the research. Major questions were developed in the form of a general statement which was then followed by a sequence of sub-questions for further probing.

The questions were then piloted with several managers from two countries. The piloting was aimed at identifying ambiguities, helping to clarify the wording of questions and permitting early detection of necessary additions or omissions.

\section{CONDUCTING THE FIELDWORK}

Purposive sampling was used in this research as a sampling strategy. The names of respondents were initially determined by the management of each organization through company record based on their job responsibilities, position and involvement in the subject studied. However, respondents were also selected on the basis of the researcher's individual judgment where permitted on the ground that they could provide the necessary information needed for the research.

Most of the fieldwork involved interviewing using semi-structured questions with various categories of respondents from the participating organizations. Besides in-depth interviewing, the researcher observed himself the process of training activities in each organization. This will be discussed later under the heading of techniques for eliciting information. As well as interviewing and observation, the fieldwork included analysis of documentary sources in each organization. Documents were collected from the organizations' resource center, individual file record, libraries of 
various universities, company reports, company newsletter and other printed materials (e.g. newspaper cuttings, journals, text books, conference reports, articles, training packages) that were made available for the purpose of the research.

\section{SEMI-STRUCTURED INTERVIEW}

The choice of semi-structured rather than structured interview was employed because it offers sufficient flexibility to approach different respondents differently while still covering the same areas of data collection. The interviews were tape-recorded to secure an accurate account of the conversations and avoid loosing data since not everything can be written down during interview. And every cassette tape was numbered and labeled with name of interviewee in order to avoid complication.

\section{PARTICIPANT OBSERVATION}

This is where the researcher observed phenomena of interest in the environment studied to draw information which was not obtainable from other methods. What had been observed by the researcher was related to the physical setting and environment within which the training activities took place. Observation generated insight and better understanding on the phenomenon under studied.

\section{DOCUMENTARY SOURCES}

This was important to supplement as well as to compensate for the limitations of other methods. Documentary evidence acts as a method to crossvalidate information gathered from interview and observation given that sometimes what people say maybe different from what people do. Additionally, documents provide guidelines in assisting the researcher with his inquiry during interview. Official and unofficial documents and records pertaining to the process of training activities in the organizations were analyzed. Thus, corroboration of multiple qualitative techniques for this case studies research therefore enhance the validity and reliability of findings.

\section{THE USE OF MULTIPLE CASE STUDIES TO ENHANCE GENERALIZATIONS}

A multiple case study was employed in the research study. The choice for multiple cases is appropriate given that Yin (1993) argues, Multiple-case studies should follow a replication, not sampling logic.
This means that two or more cases should be included within the same study precisely because the investigator predicts that similar results (replication) will be found. If such replication are indeed found for several cases, you can have more confidence in the overall results. The development of consistent findings, over multiple cases, can then be considered a very robust finding ${ }^{[13]}$.

Examining a number of organizations enhances the accuracy, validity and reliability of the results by capturing the holistic essence of the subject studied.

\section{REFERENCES}

1. Morgan, G., and L. Smircich, 1980. The Case for Qualitative Research. Acad. Manag. Rev., 5 (4): 491-500.

2. Finch, J., 1986. Research and Policy. The Falmer Press, London, pp: 6-10.

3. Easterby-Smith, M., R. Thorpe, and A. Lowe, 1991. Management Research: An Introduction. Sage Publication, London, pp: 23-25.

4. Denzin, N., and Y. Lincoln, 1994. Handbook of Qualitative Research. Sage Publicatio, California, pp: 3-5.

5. Merriam, S., 1988. Case Study Research in Education: A Qualitative Approach. Jossey-Bass Publishers, California, pp: 4-25.

6. Yin, R., 1989. Case Study Research. Sage Publication, California, pp: 22-26.

7. Anderson, G., 1993. Fundamentals of Educational Research. Falmer Press, London, pp: 152-160.

8. Patton, M., 1987. How to Use Qualitative Methods in Evaluation. Sage Publication, California, pp: 18-20.

9. Johnson, D., 1994. Research Methods in Educational Management. Longman Group, Essex.

10. Gummesson, E., 1991. Qualitative Methods in Management Research. Sage Publication, California, pp: 83-156.

11. Hartley, J., 1994. Case Studies in Organizational Research in Casell and Symon 1994 Qualitative Methods in Organizational Research. Sage Publication, London, pp: 208-229.

12. Yin, R., 1984. Case Study Research: Design and Methods. Sage Publication, California, pp: 11-15.

13. Yin, R., 1993. Application of Case Study Research. Sage Publication, California, pp: 33-35. 